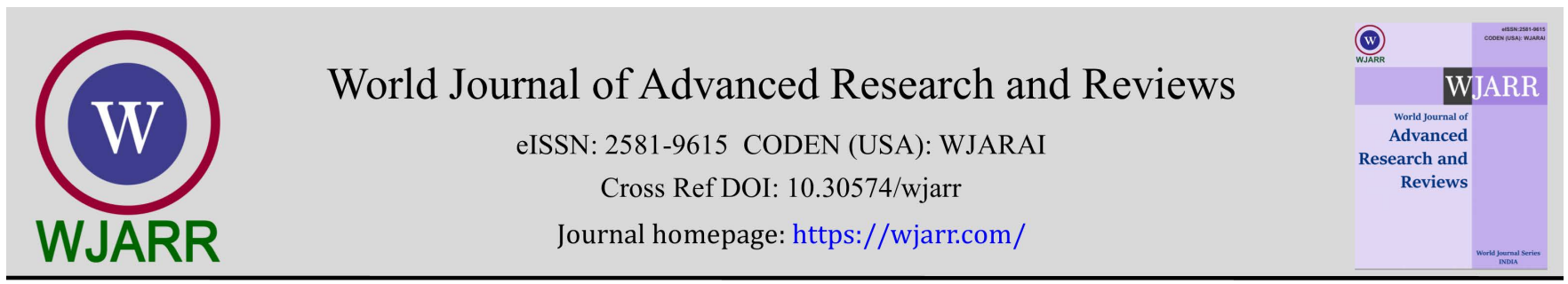

(REVIEW ARTICLE)

\title{
GM crops, farmers and consumers concerns: role of advocacy
}

\author{
SP Srivastava * \\ Department of Law and Governance, Central University of South Bihar, Gaya.
}

World Journal of Advanced Research and Reviews, 2022, 13(02), 050-056

Publication history: Received on 22 December 2021; revised on 31 January 2022; accepted on 02 February 2022

Article DOI: https://doi.org/10.30574/wjarr.2022.13.2.0096

\begin{abstract}
The production of genetically modified crops for commercial release and agriculture resulting in a number of changes in the life style of an individual and farmers particularly. Scientists who analyze the impact of agricultural biotechnology from the socio-legal perspective; looked the tall claim of genetic engineering with suspicion. They claim alterations can change the organism's metabolism, growth rate, and/or may have down side effect on external environmental factors. This research paper tries to explore and examine the concerns raised from the socio-legal perspective as society should have minimum scientific knowledge in reference to use of GMOs and its derivatives. It is concluded with the finding that a reasonable policy with regard to their use by the farmers and others stake holders need to be prepared.
\end{abstract}

Keywords: GMOs and Farmers Concern; GMO Labelling; Biosafety and Consumer Concerns; GMO Landscape and patent; Weed Resistant Herbicide and GMOs and Economic Concerns in Use of GMOs.

\section{Introduction}

Advances in agricultural biotechnology research and innovation thereto led to production of genetically modified crops for commercial release [1] and agricultural uses. This achievement is considered remarkable as the scientific knowledge of genetic engineering \& agriculture biotechnology enable scientists to alter the genetic code of all living organisms practically [2]. Consequently this innovation facilitated artificial selection for specific, desired traits; which has resulted in a variety of different organisms, ranging from sweet corn to hairless cats. Further, recent decades advances in the field of genetic engineering have allowed for precise control over the genetic changes introduced into an organism [3]. However, this is resulting in a number of changes in the life style of an individual and farmers particularly; which has raised certain serious concern with regard to social ramification, ecological balance, environment, health and economic impacts on stakeholders arising out of commercialization of agricultural biotechnology. The cultivation of genetically modified (GM) crops on millions of hectares of lands and their injection into our food chain involving all living beings have affected every stakeholder of the agriculture production chain. The industrialist and the researcher of agricultural biotechnology claimed that the most common GMO crops were developed to address the needs of farmers. However, there is another group of scientists who analyze the impact of agricultural biotechnology from the socio-legal perspective; they looked at the tall claim with suspicion. Is it actually serving the objective stated thereto and the technology used are completely controlled; without any negative impact on farmers and users of the crops and foods? There may be many purported downsides, but the evidence varies, and the health issues or environmental effects or socio- economic-ethical concerns; associated with GMOs and derivatives need to be fixed. Whether the all aspects either about the basic impact on pattern of farming or its environmental effects or health concerns have been addressed and complete literature about the findings are being disseminated or the consumers interest are being compromised for the shake of commercial gain. This research paper tries to explore and examine the concerns raised from the socio-legal perspective as society should have minimum scientific knowledge in reference to use of GMOs and its derivatives. A reasonable policy with regard to their use by the farmers and others stake holders need to be prepared acknowledging

\footnotetext{
${ }^{*}$ Corresponding author: SP Srivastava

Department of Law and Governance, Central University of South Bihar, Gaya

Copyright (C) 2022 Author(s) retain the copyright of this article. This article is published under the terms of the Creative Commons Attribution Liscense 4.0.
} 
the contribution of the scientist but with proper evaluation and display of caution in commercial use of GM crops. The literature thereto needs to be accessible pointing out the scientific truths of the down sides of the genetic modification on environment, health, and in social fabric.

\section{Relative control in genetic modification- positive and negative sides}

It is a well-accepted fact in genetic engineering that when a foreign gene is inserted in other organism for a particular desired component and traits; the complete control in terms of relative reactions within the body of an organism cannot be applied. Moreover, it is alleged that there may be many unknown ramifications due to altering the natural state of an organism through foreign gene expression [4]. After all, such alterations can change the organism's metabolism, growth rate, and/or response to external environmental factors [5]. Even it is contented that the issue of compatibility and adjustment with foreign or alien environment and with organism cannot be ruled out [6]. It is reported that there is no or a significantly small amount of protein or DNA remaining in vegetable oil extracted from the original GM crops [7]. It is also claimed that the refining process removes nearly all non-triglyceride ingredients [8]. It is evident that the possibility of negative impacts cannot be denied hence farmers or consumers should necessarily be nudged with the positive and negative side of the coin.

Moreover, most of the consumer lack basic information, even many a times they don't know that they are eating genetically engineered foods. As more than $60 \%$ of all processed on the supermarket like pizza, chips, cookies, salad etc. are containing ingredients from genetically modified crops soybean, corn and canola. Controversies and public concern surrounding GM foods and crops commonly focus on human and environmental safety, labeling and consumer choice, intellectual property rights, ethics, food security and environmental conservation. For understanding each and every risk and for getting actual and complete benefit of the technology, the education thereto could place a vital role. The consumers and the farmers as a first user need to be acquainted about the all inter related effect along with the environmental concern, its impact on soil character or any health-related concerns thereto. Advocacy and conspicuous information with regard to concerns need to be addressed through execution of policies with effective execution.

For imparting effective education to the stakeholder; awareness as well as sensitization could be an effective intertwined mechanism. As the farmers and majority consumers are not of well-read class or conscious segment; the duty of the policy makers is double fold. The concerns need to be addressed through multi-layered strategy classifying focused two groups who are likely to be affected by the GMO and their food; the first one is producer and second one is consumer. Because this is fundamental rights of farmers and consumers. Devising an effective policy and educating the stakeholder will only ensure the guarantee of right to live in unpolluted environment. The farmers are entitled to know the long term as well as immediate effect on the land, crops, environment and on their health and what cost they are going to pay if adopted the GMO seeds. Equally the consumer should also be given prior information up to date regarding each aspect particularly the health hazard, as well as which crops and food contain the genetically modified organisms. It should remain dynamic subject to whatever new findings are coming and a policy modifications should be made as and when it is required, as many of the apprehensions may not be true.

\subsection{GM Crops and Farmers Concern}

The pressure of population and more and more demand of foods around the globe is the cause of accepting high yielding varieties and farmers are scrambling to find new options for survival. In addition, there is increasing concern about the degradation of our natural resources, deforestation, qualitative changes in soil characteristics. Moreover decreasing size of agricultural land due to more family members have changed the role of farmers in the metrics of agricultural products. It is claimed that the use of GMOs and foods thereto shall increase farm income, facilitate positive land stewardship, and contribute to rural sustainability and it should be encouraged. Though through technology, farmers may have better opportunity which may indirectly lead to impact national economy; but it cannot be kept at abeyance that when any negative impact will occur then only the legislator shall awake and ponder upon the loss; a policy framework shall be prepared later when the hidden impact may already have affected badly. We have a bitter experience how the green revolution has badly affected the soil characteristics and many farmers lands turned as barren land. While many farmers say they are pleased with GMO varieties, many others are disappointed, finding mixed results or facing new problems in the extremely concentrated and corporate-dominated seed sector. It became a more serious issue in country like India where the legislative agencies are being blamed that they give priority to corporate interests. These GMOs may affect all farmers, whether or not they plant GMO seeds; as we witness in some cases that the nearby crops are also got traits of GMO neighbour field.

Moreover, the concentration of private players in agricultural research and their response to farmers concern are also a serious concern. Privatization and monopolistic nature of the market is also a hurdle to adopt GMOs by the farmers. 
Today; just four companies control almost $60 \%$ of the seed market. For certain crops, the market is even more concentrated. The "big four" seed companies - Monsanto, DuPont, Syngenta and Dow - own 80\% of the corn and 70\% of the soybean market. In addition, the corporate in Indian market don't prefer to share each and every information related therewith. Farmers do not have sufficient knowledge with regard to genetic engineering technology, consequences of using GMOs, research data of field trial and different legislative mandates. The Farmers' faces problems like rejection of their crops in export, their others non-GMOs crops are getting adverse effect even there is use of normal seed, contamination, the claimed traits are not reflected uniformly, more over the farmers may develop health issues as claimed by the few researchers.

\subsection{Biosafety and Consumer Concerns}

There are many biosafety issues with regard to GM foods including toxicity, allergenicity, antibiotic resistance, eating of a foreign DNA, use of promoters of virus origin, changes in nutritional level, gene flow, resistance of target species, impact on biodiversity, ethical issues etc. [9]. Concerns have been expressed regarding potential risks associated with GM foods from the human health and environment perspectives. It is claimed that horizontal gene transfer of pesticide, herbicide, or antibiotic resistance to other organisms would not only put humans at risk, but it would also cause ecological imbalances, allowing previously innocuous plants to grow uncontrolled, thus promoting the spread of disease among both plants and animals [10]. In addition, the studies revealed; when a new transgene is introduced into a wild fish population, it propagates and may eventually threaten the viability of both the wild-type and the genetically modified organisms [11]. Genetic modification and "biosafety" are concepts that have not been well understood by, or accessible to, the non-geneticists [12]. Moreover, it is contended that the effects of changes in a single species may extend well beyond to the ecosystem. Single impacts are always joined by the risk of ecosystem damage and destruction [13]. The increasing number of reports on ecological risks and benefits of GM plants stresses the need for experimental works aimed at evaluating the impact of GM crops on the natural and agro-ecosystems [14]. Copies of a gene may be integrated, additional fragments inserted, and gene sequences rearranged and deleted-which may result in lack of operation of the genes instability or interference with other gene functions possibly cause some potential risks [15]. There is no common consensus or no inclusive information on definitive negative impact of GMOs on human health and environment, even if the scientific evidences are still emerging [16].

Consumer is the one who is direct and ultimate stakeholders with regard to GMOs and derivatives. consume. But the really consumer don't know about their food. Although the genetically modified organisms (GMOs) have been available for commercial purchase since the 1990s, allowing producers to increase crop yields through bioengineering that creates herbicide-resistant and insect-resistant varieties. However, consumers' knowledge about GMOs has not increased at the same rate as the adoption of GMO crops [17].

\subsection{GMO Landscape and Patent Laws}

GMO landscape is well documented. According to the International Journal of Food, landscape almost 400 cases of GMO contamination occurred between 1997 and 2013 in 63 countries. Many plants are pollinated by insects, birds or wind, allowing pollen from a GM plant to move to neighboring fields or into the wild [18]. This "genetic drift" illustrates the enormous difficulty in containing GMO technology. Not only is genetic drift impossible to prevent, inadequate regulation also fails to hold seed companies accountable for any resulting damages and ultimately puts the onus on farmers who have been the victims of contamination.

For farmers, the consequences have been severe and it could affect it; but the extent is yet not completely assessed. Contamination can spark dramatic economic losses for farmers who face rejection from export markets that ban GMOs. Organic farmers suffering contamination can lose their organic certification and the premium they earn for their organic crops.

Farmers who buy GMO seeds must pay licensing fees and sign contracts that dictate how they can grow the crop - and even allow seed companies to inspect their farms. GMO seeds are expensive and farmers must buy them each year or else be liable for patent infringement. And while landscape can happen through no fault of their, farmers have been sued for "seed piracy" when unauthorized GMO crops show up in their fields. Crops have been contaminated by GMOs due to improper equipment or facility cleanout, or lack of other necessary precautions.

Farmers who don't know the patent laws, companies are suing for the seed piracy. Because the right of re-plant from seed is the right of farmer but this is not allowed to GM seeds. In David versus Monsanto, court observed that great lengths to enrich the Roundup Ready canola plants that originated from his neighbor's land: by treating his crops with Roundup, he ensured that only the resistant strains persisted. In the following seasons, he replanted the seeds without having a licensing agreement with Monsanto. The unusually high prevalence (95-98\%) of tolerant plants in Schmeiser's 
fields clearly demonstrated infringement in the eyes of the court, and Monsanto claimed rightful remedy for its loss of profit [19]. The US Supreme Court in Bowman v. Monsanto [20] introduced a legal doctrine called patent exhaustion, which states that patent rights are applied only to the first sale [21]. Based on this doctrine, Indiana farmer Vernon Bowman, who replanted the seeds and Monsanto claimed that the right to "use" a patented item did not include reproducing it. The court ruled in favor of Monsanto [22].

Now, it is certainly mandatory and in the interest of agricultural industry and farmers that they should know their rights. As farmers don't know the legality of the patented GMOs, growing use of GMOs and crops may again and again place them in legal trappings. Moreover, they need to be educated that they cannot preserve the seeds without permission for the next year with complete legal aspects thereto as they can't understand what they do. There is need of proper advocacy with regard to distribution of the GM seeds among farmers. The Government may also adopt a policy guideline that the farmers are the lifeline of food chain their few conducts are exempted from the legal restrictions of the patent.

\subsection{Weed Resistant Herbicide and GMOs}

GM plant agriculture has led to superweeds and superpests that are extraordinarily difficult for farmers to manage. The first herbicide resistant weeds found in the USA, with herbicide but the popular herbicide glyphosate introduced in 1974 and paired with some GMO crops in 1996. Introducing this herbicide resistant GMO came and production increased but in 1996 this glyphosate weed paired with GMO and produce resistant weeds. Now whatever benefits through herbicide resistant GMO to farmers were predicted it goes vain; since introduction of weed resistant herbicide. It is evident that the introduction of glyphosate-resistant crops, about 38 weed species worldwide have been identified that have developed resistance to glyphosate. As a result, these so-called superweeds can continue to infest fields and siphon nutrients from the valuable crops planted there, leading farmers to use other costlier - and potentially harsher - herbicides to control them [23]. Now the farmer forced to use chemical for remove the weeds. This is expensive for the farmers. Even consumers who fear trace chemicals in the food supply [24]. Farmers affected by resistant pests must revert to older and more toxic chemicals, more labor, which overshadows the promised benefits of GMO technology. Herbicides, including glyphosate, can also increase plant diseases by altering plants' ability to absorb nutrients and reduce soil health by killing microbes. These chemical-dependent strategies, peddled by major chemical and biotech companies, will keep farmers dependent on increasingly toxic pesticides in a race that nature always wins [25].

Thus farmers has no idea about the GMO intricacies and they do not know that the claimed ben efits are resistance to superweeds and superpests. They do not have sufficient knowledge about GM plants. It is necessary for farmers to know about the pros and cons of the GMOS. Because as they don't have knowledge then how to deal with the problems of super weeds and if they purchase seed then what are the responsibility of companies. This awareness may protect them from losing everything and protecting environment and society.

\subsection{Economic Concerns}

Most of the researcher across the nation claim and shown their concerns with regard to economic strides of the GMOs and apprehension has been made that private companies will claim ownership of the organisms they create and not share them at a reasonable cost with the public [26]. It is argued that use of genetically modified crops will hurt the economy and environment, because mono-culture farming practices by large-scale farm production centers (who can afford the costly seeds) will dominate over the diversity contributed by small farmers who can't afford the technology. It is asserted that GM crops could impact food availability by providing seeds which are resistant to adverse climate conditions; have an effect on food access by increasing farmers' incomes; and, under the same food utilization conditions, bio-fortified crops could increase the nutritional status of households worldwide. The magnitude of these impacts varies by country and year, and is mainly due to prevailing costs of different herbicides used in GM HT systems vs. conventional alternatives, the mix and amount of herbicides applied, the cost farmers pay for accessing the GM HT technology, and levels of weed problems [27].

\section{Knowledge of GMOS and its impact in the society}

A survey conducted by the Food Policy Institute at Rutgers University found that US consumers as a whole were fairly unknowledgeable about GMOs, with just 48\% knowing that GMOs were available in supermarkets and only $31 \%$ believing that they have most likely consumed a GM product. The majority of participants also self-rated their knowledge to be poor; $48 \%$ said that they knew very little about GMOs, whereas $16 \%$ felt they knew nothing at all, compared with 30\% knowing a fair amount and just 5\% knowing a great deal about GMOs [28].

Knowledge of GMOs is an area of interest because it may affect consumer opinions, attitudes, and behaviors. In a 2001 survey of US citizens, only $44 \%$ felt that they had at least some information about GMOs, with just $9 \%$ receiving a great 
deal of information. However, 54\% had heard not much or even nothing about biotechnology and food. A large amount of indecision accompanied this lack of information, with $46 \%$ of consumers not knowing what to think about GM foods and their degree of safety, 29\% finding them safe, and 25\% feeling that they were unsafe [29] However, attitude toward GMO safety may be a result of limited awareness, because it was not stable for some consumers; after reading that over $50 \%$ of foods available in grocery stores contained GM ingredients, $20 \%$ of participants who originally found GMOs unsafe changed their answers [30]. Consumer has knowledge about the what are they eat and also their consumer rights of their product first one labeling and effect on health.

According to a recent survey from GMO Answers, nearly 70\% of US adults don't understand what GMOs are and only one-third are comfortable having GMOs in their food. This despite the fact is that the majority (60-70\%) of processed grocery store products contain some GM ingredients in USA.

\section{Labelling of GMO and right to know}

The debate over foods derived from genetically modified (GM) crops often touches on the subject of labeling. Many consumers argue and insist on their right to know what they are eating and their right to choose [31]. As a result, many governments have begun to heed these suggestions and have either implemented labeling regulations or are working on them. Before any labeling rules can be implemented, governments would have to set up standards and services to conduct testing of the presence of GM ingredients; certification; and ensure that the quality standards are clear and achievable [32].

Current regulations are based on the chemical characteristics of the food product and not on the way the product was made. In Canada, special labeling is required for all foods; manufacturers can choose to label products to provide information regarding the presence or absence of GM ingredients, with safety concerns such as allergenicity and compositional or nutritional changes are identified. In the US, all foods must be labeled when there are health concerns. In 1992, the FDA published a Statement of Policy announcing that GE foods did not require labeling because they were not materially different from nonmodified versions, and under the Federal Food, Drug, and Cosmetic Act, only material information needed to be included on a label [33]. In January 2001, the Food and Drug Administration provides guidance to manufacturers in the appropriate, truthful and non-misleading labeling of foods and provides examples of acceptable and unacceptable labeling language.

The process for approval of GM foods in the EU is strictly regulated, with all new GM crops having to be presented to the European Food Safety Agency for a thorough risk assessment, after which the European Commission presents the results to the public, brings the resulting comments back to the Food Safety Agency, and then makes a final decision whether or not to grant authorization for the next 10 years [33]. Unlike the United States, the European Union has enforced mandatory labeling and strict traceability of all bioengineered food, including any product, food, or animal feed produced from GMOs, since 1997 [34]. In 2006, India proposed a draft rule requiring the labeling of all genetically modified (GM) foods and products derived thereof However, still there is no working policy of labelling.

\section{Conclusion}

It is evident from the above discussion, that the knowledge of GM Crops and its ramifications are little known to the farmers and users. In addition, under the global mandates to right to health it is necessary that all the stakeholders must be equipped with sufficient knowledge with regards to GM Crops. Farmers have less education about the GMO although, they have bought the seeds. There is need to systematic education about the pros and cons of the GMOs. Whatever, the most important is that technology is growing, must be provide the education related to those technologies.

GM products have been in the food system for decades and are becoming even more present, yet consumer knowledge and awareness are not improving accordingly. Surveys show that large percentages of consumers are unaware of GMOs or do not fully understand GM products, their traits, and their effects, and they themselves are dissatisfied with their self-rated knowledge, indicating a desire and a need for widespread consumer education.

Although consumers across the globe support mandatory GMO labeling, the limited extend of consumer knowledge regarding GMO characteristics, processing, and effects may present an issue for actual interpretation of the labels. Experts in the field should consider methods of educating the public more thoroughly so that they can use the information about GM contents responsibly and make fully informed judgments about their food choices. 
Adequate consumer education appears to be the missing puzzle piece. The same GMO Answers survey found that a majority of consumers want to know more about the impact of GMOs on health and food safety. But what is the food industry - growers, suppliers, processors and retailers - to do about this? Consumer education comes at a high cost, and not all supply chain members in the food industry have the resources to fund a wide-spread educational campaign. At first glance, it appears the use of product labeling specifically for GMOs would be the answer. However, many consumers already are confused by the variety of labels currently on the food they purchase, making it difficult for families to make decisions at the grocery store.

\section{References}

[1] In 2002 approval for the commercial release of Bt cotton hybrids/ varieties resistant to cotton bollworm was given. See, Press Release dated $15 \mathrm{sep}, 2020$ by the Ministry of Agriculture and farmers welfare. 2020.

[2] Rashidah Begum Gelamdin, Norlidah Alias, Mohammad Attaran. “Students' and Teachers' Perspectives on Biotechnology Education: A Review On Publication in selected journals Department of Curriculum and Instructional Technology. Faculty of Education, University of Malaya, Kuala Lumpur, Life Sci J 2013; 10(1): 12101221.

[3] Phillips T. Genetically modified organisms (GMOs): Transgenic crops and recombinant DNA technology. Nature Education. 2008; 1(1): 213.

[4] Such alterations can change the organism's metabolism, growth rate, and/or response to external environmental factors. These consequences influence not only the GMO itself, but also the natural environment in which that organism is allowed to proliferate. Potential health risks to humans include the possibility of exposure to new allergens in genetically modified foods, as well as the transfer of antibiotic-resistant genes to gut flora. See, Phillips, T. Genetically modified organisms (GMOs): Transgenic crops and recombinant DNA technology. 2008; 1(1) Nature Education 213.

[5] Lobo, I. Environmental influences on gene expression. Nature Education 2008 1(1):39

[6] National Research Council (US) Committee on Identifying and Assessing Unintended Effects of Genetically Engineered Foods on Human Health. Washington (DC): National Academies Press (US). 2004.

[7] AS Bawa, KR Anilakumar. Genetically modified foods: safety, risks and public concerns-a review. J Food Sci Technol. 2013; 50(6): 1035-1046.

[8] Crevel RWR, Lerkhof MAT, Koning MMG. Allergenicity of refined vegetable oils. Food Chem Toxicol 2000; 38(4): 385-393.

[9] Jasleen Kaur. Genetically modified organisms and biosafety issues. Indian J. Adv. Res. Soc. 2016; 1(1): $103-107$.

[10] Gijs A. Kleter, Ad A. C. M. Peijnenburg, and Henk J. M. Aarts. Health Considerations Regarding Horizontal Transfer of Microbial Transgenes Present in Genetically Modified Crops. J Biomedicine Biotechnology . 2005(4): 326-352.

[11] William M. Muir. The threats and benefits of GM fish. EMBO Rep. 2004 Jul; 5(7): 654-659.

[12] Divine Nkonyam Akum at al. Social and Economic Issues - Genetically Modified Food in Food Industry edited by Innocenzo Muzzalupo, Intechopen. 2013.

[13] PK Rai, JS Singh. Invasive alien plant species: Their impact on environment, ecosystem services and human health. Ecological Indicators. Apr 2020; 111: 106020.

[14] M Buiatti, Christou, G Pastore. The application of GMOs in agriculture and in food production for a better nutrition: two different scientific points of view Genes. Nature. May 2013; 8(3): 255-270.

[15] Dhan Prakash, Sonika Verma, Ranjana Bhatia, BN Tiwary. Risks and Precautions of Genetically Modified Organisms. International Scholarly Research Notices. 2011; 13.

[16] Motbaynor Terefe. Biosafety Issues of Genetically Modified Crops: Addressing the Potential Risks and the Status of GMO Crops in Ethiopia. Clon Transgen 2018; 7: 2.

[17] Wunderlich S, Gatto KA. Consumer perception of genetically modified organisms and sources of information. Advances in nutrition (Bethesda, Md.). 2015; 6(6) 842-851.

[18] Price B, Cotter J. The GM Contamination Register: a review of recorded contamination incidents associated with genetically modified organisms (GMOs). Food Contamination. 2014; 1: 5. 1997-2013.

[19] Monsanto Canada Inc. v. Schmeiser (2004) 1 S.C.R. 902, 2004 SCC 34 (Canadian Supreme Court Decision) 569. 
[20] U.S. 278. 2013.

[21] IMPRESSION PRODUCTS, INC. V. LEXMARK INTERNATIONAL, INC. No. 15-1189. Argued March 21, 2017Decided May 30, 2017.

[22] Wright BD. Plant Genetic Engineering and Intellectual Property Protection. Agricultural Biotechnology in California Series, Publication No. 8186. 2006.

[23] Holly Whetstone. Superweeds, secondary pests \& lack of biodiversity are frequent GMO concerns. Michigsn State University 15 August 2018.

[24] Anna Meyer. Food and Water Watch. What are "Superweeds"? https://geneticliteracyproject.org/gmofaq/what-are-superweeds/.

[25] Johal GS, Huber DM. Glyphosate effects on diseases of plants. European Journal of Agronomy. 2009 31(3):144152.

[26] Demont M, et al. GM crops in Europe: How much value and for whom? Euro Choices. 2007; 6: 46-53.

[27] Graham Brookes \& Peter Barfoot. Economic impact of GM crops. G M Crops Food. Jan-Mar 2014; 5(1): 65-75.

[28] Hallman W, Hebden W, Cuite C, Aquino H, Lang J. Americans and GM food: knowledge, opinion \& interest. New Brunswick (NJ): Rutgers, the State University of New Jersey, Food Policy Institute. Nov 2004; 1104-007.

[29] Ken Donaven, Chelsea May. Who Should Be Responsible for Consumer Education on GMOs? 2018. https://martecgroup.com/gmo-consumer-education/.

[30] Pew Initiative on Food and Biotechnology. Pew initiative on food and biotechnology finds public opinion about genetically modified foods "up for grabs." 2001 March 26.

[31] Wunderlich S, Gatto KA., "Consumer perception of genetically modified organisms and sources of information" Advances in nutrition (Bethesda, Md.). 2015; 6(6) 842-851.

[32] Pocket K No. 7: Labeling GM Foods, https://www.isaaa.org/resources/publications/pocketk/7.

[33] Federal Food, Drug, and Cosmetic Act. United States Code, 2006 Edition, Supplement 3. Subchapter IV: Food. [Internet]. United States Food and Drug Administration; [cited 2014 Dec 4].

[34] European Commission [Internet]. Food and feed safety: biotechnology. European Union; c1995-2015. 